\title{
e-interview
}

columns

\section{Michelle B. Riba}

Michelle Riba is Professor and Associate Chair for Integrated Medicine and Psychiatric Services, Department of Psychiatry, University of Michigan and Director, Psychooncology Program, University of Michigan Comprehensive Cancer Center. She trained at the University of Connecticut. Her special interests include the clinical, research and teaching aspects of psychosomatic medicine.

\section{If you were not a psychiatrist what} would you do?

I would have liked to be an oncologist. I was actually strongly debating between the two fields and took many electives in oncology. I now spend much of my time at the University of Michigan Comprehensive Cancer Center and so have been able to combine both psychiatry and oncology.

What has been the greatest impact of your profession on you personally? Psychiatry has afforded me a wonderful opportunity to continue to learn, to stay excited about my work, and I think has made me a more compassionate and understanding person. Every time I see a patient or teach a student, I learn something.

\section{Do you feel stigmatised by your} profession?

I do not personally feel stigmatised but I do believe that our patients feel stigmatised and in many cases they are. In the United States, healthcare insurance, reimbursement and lack of parity for psychiatric conditions, including substance use disorders, continue to place psychiatric disorders on an unequal footing with other medical conditions.

\section{Which book/text has influenced you most?}

I have been influenced by a lot of the work of Melanie Klein and also of Irvin Yalom.

What research publication has had the greatest influence on your work? John McIntyre and John Romano wrote an article entitled 'Is there a stethoscope in the house (and is it used)?' (Archives of General Psychiatry, 34, 1147-1151). The article was trying to determine if graduates of a psychiatry residency programme continued to use their stethoscopes. I thought this was an important and interesting article because it reminds us that as psychiatrists, we are doctors first. We need to appreciate the importance of not giving up cer tain skills that we learned in medical school and residency.

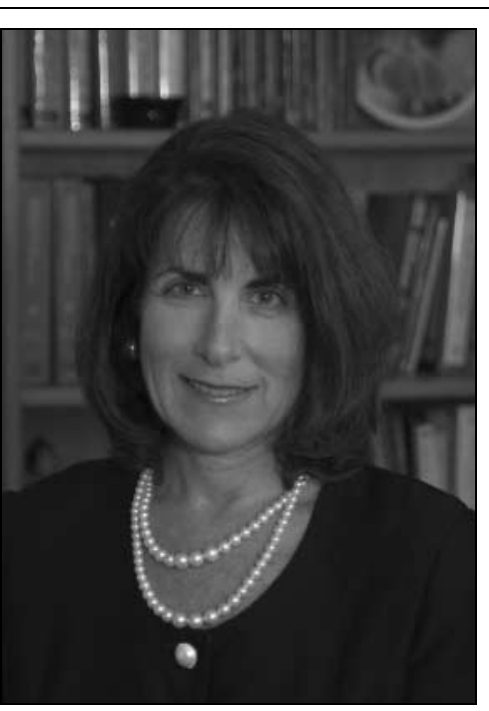

not doing as well as we probably could in anticipating the great need for psychiatric services worldwide, and how we are going to accommodate such an important need.

How would you entice more medical students into the profession?

Students enjoy learning from excellent teachers, seeing patients in a supportive environment, and being able to help patients and families. If we as a profession can provide better role models, and more opportunities for mentorship and helping students see the rich research and clinical challenges, I believe we will continue to see more students interested in psychiatry.

What is the most important advice you could offer to a new trainee? One of the most critical determinants for a trainee is to find a good mentor(s) who could help advise and nourish the trainee's

What part of your work gives you the most satisfaction?

Someone wise once told me that I should never give up seeing patients. This was excellent advice. Seeing patients and families gives me the most satisfaction in my work.

What do you least enjoy?

Documentation that really doesn't further or enhance patient care but is basically done for bureaucratic reasons annoys me a lot!

\section{What is the most promising} opportunity facing the profession? As a psychiatrist working in psychosomatic medicine I believe that the interface between medicine and psychiatry affords us spectacular opportunities to help our patients. Work by Nancy Frasure-Smith and others is exciting regarding the role of depression in post-myocardial infarction, as but one example.

\section{What is the greatest threat?}

In the United States, it is gross underfunding of psychiatric care and lack of services. The President's New Freedom Commission determined that our mental health system is in disarray and is 'broken'.

\section{What single change would}

substantially improve quality of care? Parity (non-discrimination) for psychiatric care and services. In the United States, if legislation required psychiatric disorders to be treated and 'covered', as are other medical conditions, it would go a long way to help provide care for patients.

Do you think psychiatry is brainless or mindless?

think psychiatrists and our profession could do a better job about setting research and clinical agendas and priorities. We are career. There are different ways that training programmes help trainees in this respect - but I believe that membership is a very important part of success.

What is the future for psychotherapy in psychiatry training and practice? The Residency Review Committee in in a number of psychotherapy domains, so that when residents graduate they are deemed competent. I believe that more research data show that the combination of psychotherapy and pharmacotherapy for a number of disorders is more efficacious than either treatment alone. These factors portend well for the future of psychotherapy in residency training and practice.

\section{What single area of psychiatric} research should be given priority? Brain imaging should be given high priority as well as molecular genetics. If we better understand the biology of disorders, we will be able to develop better treatments and care.

\section{What single area of psychiatric} practice is most in need of development?

The issue of work disability is an important area. Too often by the time psychiatrists see patients, the insurance companies and lawyers have made it virtually impossible for us to be of help. We need to look at other models for helping people who become disabled and help them get back to satisfying work, school, or other occupation so they can feel good about themselves and their lives.

Dominic Fannon Psychiatry has promulgated competencies 